\title{
Levoglucosan as a Tracer for Smouldering Fire
}

\author{
Dan Madsen* (1), Division of Fire Safety Engineering, Lund University, Lund, \\ Sweden \\ Hafiz Abdul Azeem (10), and Margareta Sandahl (10, Department of Chemistry, \\ Centre for Analysis and Synthesis, Lund University, Lund, Sweden \\ Patrick van Hees (10), and Bjarne Husted (10), Division of Fire Safety Engineering, \\ Lund University, Lund, Sweden,
}

Received: 22 December 2017/Accepted: 8 September 2018

\begin{abstract}
Detecting fires at an early stage is crucial for mitigating and extinguishing fires. The increased use of biofuels in Northern Europe has led to an increased number of fires in storage facilities. These fires are often caused by self-heating in the interior of the stored materials and slowly develop to smouldering fires. Consequently, these smouldering fires are usually detected several days or weeks after the initial smouldering fire had started. At this point, measures to extinguish the smouldering fire inside the material are difficult as the fire has grown for a long time and is located inside the material. This makes it difficult to gain a successful effect of any extinguishing agents. This paper presents a pilot study in lab scale suggesting levoglucosan as an early tracer for smouldering fires using $600 \mathrm{~g}$ cotton as the biomass source. The advantage of detecting levoglucosan as a fire signature is that it serves as a tracer compound for biomass burning and is produced at temperatures of 200$400^{\circ} \mathrm{C}$ reducing the risk of false alarms from emissions produced at lower temperatures. In this paper, levoglucosan was detected in aerosols emitted in an early stage from smouldering fires and was analyzed by ultrasonic assisted extraction followed by gas chromatographic separation and mass spectrometric detection. First detection of levoglucosan was made in the first sample, collected after 30 min when the smouldering fire was only a few cubic centimeters of the cotton package. In addition, levoglucosan was found in the solid residues of carbonized cotton after the initial smouldering process had moved through the material. The findings should be regarded as screening results to be used for the development of sensors and technology for smouldering fire detection.
\end{abstract}

Keywords: Self-heating, Autoignition, Biofuels, Electronic nose, Fire detection, Smoldering fire

\footnotetext{
* Correspondence should be addressed to: Dan Madsen, E-mail: dan.madsen@brand.lth.se Dan Madsen and Hafiz Abdul Azeem have contributed equally to this work.
} 


\section{Introduction}

The increased use of solid wood-based biofuels in the power industry in Northern Europe has led to an increased number of fires in storage facilities, both in enclosures and outdoors [1]. The fires have been caused both by external ignition of biofuels through fires in adjacent objects, overheating of process equipment and also by self-heating and autoignition of the biofuel inside the stored material. Preventing external ignition and overheating of adjacent objects are often handled by risk analysis at the specific power plant. Control of these fires is mostly straight-forward work for rescue service, yet demanding a lot of resources. On the other hand, autoignited fires inside the stored biofuels are more difficult to prevent and detect since they appear as smouldering fires with slow propagation inside the stored material. Consequently, these fires have often grown for several days or weeks before detection and are therefore more difficult to mitigate and extinguish due to the size and location. The self-heating of biomaterials are initially caused by natural microbiological degradation of the organic compounds [2]. The microbiological degradation then leads to an increased heat build-up within the material if the surrounding material does not conduct the heat to the storage surface at the same rate. As the biological processes decrease at around $80^{\circ} \mathrm{C}$ [3], chemical reactions propagate. These reactions are mostly exothermic and can cause heat buildup. Melin [3] points out a run-off temperature of $160^{\circ} \mathrm{C}$ where the temperature is fast-rising and leads to autoignition.

During the heat build-up, the biofuel starts to produce gaseous and solid products in an endothermic pyrolysis process that can be followed by an exothermic oxidation process of the produced pyrolysis products if oxygen is available. When gaseous pyrolysis products are oxidized, flaming combustion occurs. In contrast to when solid products are involved in the oxidation process, a smouldering combustion takes place [4]. So the oxygen concentration in the bulk material influences the type of combustion.

For both types of ignition, early detection is desired to mitigate the consequences of the fire. Today fires are primarily detected through the following four signatures (of fire): (1) radiation, (2) gases, (3) aerosols and (4) temperature [5]. For the autoignited fires inside the material, the fire signatures: (1) radiation and (4) temperature are not likely as indicators for early detection. Rather, indicators such as (2) gases and (3) aerosols are more likely to indicate early detection of a fire from the inside of the biofuel storage as these spread through buoyancy forces. The most commonly used reference gases for indicating fire and fire properties are carbon monoxide $(\mathrm{CO})$ and carbon dioxide $\left(\mathrm{CO}_{2}\right)$, the emission of $\mathrm{CO}$ especially for smouldering fires with an oxygen deficit [6]. Unfortunately, as explained by Melin [3], these gases are also produced during the whole interval of normal biological degradation of organic compounds and it can therefore be difficult to determine if the gas is produced from normal degradation or from a fire in an early stage. Aerosols are used as indicators of fire in common fire alarms as their physical presence indicates soot. The production and development of aerosols in fire gases are often due to various particle-gas interactions where chemical substances emitted from fires condense at particles and produces aerosols that grow 
in size. Analyzing the constituents of aerosols from fires can give valuable information of the emissions of chemical substances produced from fire. One such constituent is levoglucosan. Merlet et al. [6] points out levoglucosan (1,6-anhydro- $\beta$ glucopyranose) as the major product from pyrolysis of cellulose and as cellulose accounts for $40-50 \%$ of the total biomass [7], the yield of levoglucosan is of interest from a fire detection point of view. Research by Cordell et al. [8] pointed out that levoglucosan was mainly produced during thermal degradation of cellulose between $200^{\circ} \mathrm{C}$ and $250^{\circ} \mathrm{C}$ and has not been detected at temperatures $>400^{\circ} \mathrm{C}$. An advantage of using levoglucosan as a tracer for fire in biomaterials is that it is not a naturally occurring substance in ambient conditions in air [9] and it is seen as a very stable substance at least within an $8 \mathrm{~h}$ interval [10]. The emitted amounts of levoglucosan are typically $40-1200 \mathrm{mg}$ per $\mathrm{kg}$ combusted wood [10]. Levoglucosan is released by pyrolysis of cellulose; being a hygroscopic molecule it undergoes hygroscopic growth and possible condensation onto other particles leading to stable atmospheric aerosols [11], which allows sampling of aerosols as an initial preferred method for detecting the presence of levoglucosan.

In an interesting study by Joseph et al. [12], thermogravimetric analysis, differential scanning calorimetry, fourier transform infrared spectroscopy and a tube furnace was used to determine the major thermal degradation products from some ligno-cellulosic materials. The tested materials were wood, white paper and cardboard samples. Preparations and measurement to detect levoglucosan with an enose based on metal oxide sensors (MOS) were also carried out. In the study, a chemical substance similar to levoglucosan was identified as one of the product from combustion in the tested lingo-cellulosic materials but it could not be confirmed as levoglucosan. Therefore, the authors recommended identification and confirmation of levoglucosan as a tracer for smouldering fires by more robust method like Gas Chromatography-Mass Spectrometry (GCMS). GCMS has been successfully used by Martinsson et al. [9] and others [13] for the estimation of levoglucsan in atmospheric aerosols. The GCMS method is selective for the determination of levoglucosan at trace level amounts. There is a potential of using GCMS and online mass spectrometric methods e.g. aerosol mass spectrometer to monitor emissions from stored biomass with risks of smouldering fire by offline and online measurements, respectively. On the other hand, E-nose technology is also regarded by other authors as Kanakam et al. [14] to not only have the potential to detect fire in an early stage but also to reduce false alarms by providing the e-nose with information about fire caused gases as well as non-fire products that can cause false alarms.

This paper focuses on the identification of levoglucosan as potential tracer for early detection of smouldering fires in cotton. The reason for using cotton as a base material for detection of levoglucosan is that cotton is nearly pure cellulose and thereby a normal component in wood biomaterial. Simoneit et al. [10] presented the cellulose content in wood to be $40-50 \%$ of the dry weight. The used setup with cotton and heating wire for ignition derives from the work of Hagen [15] that uses cotton as a base material for smouldering studies. Cotton is also presented by Rein [16] to sustain smouldering fires together with other solid materials as wood and coal. To initiate the smouldering fire as from autoignition of 
biomaterials, the heat released from the heating wire was tried out as a minimum to obtain a sustained smouldering fire inside the cotton package. Furthermore, the autoignition of wood pellets followed by a smouldering fire is also presented by van Hees et al. $[17,18]$ that also performed experiments on wood pellets, leading to smouldering fires. In addition to detection of levoglucosan, mass loss and temperature profiles of the tested material were also studied in order to understand how the smouldering process develops in controlled experiments. The performed experiments of smouldering fire in this paper is in small scale, yet the presented results from smouldering fire are seen as comparable to smouldering fire in a large-scale storage of biofuels. To our knowledge no dedicated study has been performed so far to finally establish levoglucosan as a potential tracer for early detection of smouldering fires.

\section{Experimental}

\subsection{Chemicals and Materials}

Following substances and materials were used for calibration, validation of analytical method and base material for performing the experiments. Levoglucosan (1,6-Anhydro-beta-D-glucose) and N,O-bis(trimethylsilyl)trifluoroacetamide (BSTFA) containing 1\% trimethylsilyl chloride (TMCS) were purchased from Sigma-Aldrich (St. Louis, USA). Hexane from Scharlau (Spain), 1-Phenyldodecane from Acros Organic (Geel, Belgium), methanol from Scharlau (Spain) and dichloromethane was purchased from VWR Chemicals (France). Helium gas (99.999\%) for GCMS analysis was purchased from AGA, (Växjö, Sweden). The experiments were performed on commercially bought cotton, $600 \mathrm{~g}$. The brand of the cotton was COOP $200 \mathrm{~g}$ and bought at the largest COOP grocery store in Lund, Sweden.

\subsection{Experimental Setup}

The fire experiments were performed by using the ventilation and soot sampling connection at a standard cone calorimeter [19, 20] together with some external equipment for diverting a sub flow of fire gases. The experimental setup is presented schematically in Fig. 1. The setup (2) of the smouldering fire in cotton was placed on a scale (1) to log the mass loss and surrounded by a protection hood (3). The emitted reaction products from the smouldering fire where transferred by air suction from the setup into the ventilation duct (4) by forced ventilation with an air flow of $24 \times 10^{-3} \mathrm{~m}^{3} / \mathrm{s}$. The resulting average air velocity inside the protection hood and around the setup was $0.15 \mathrm{~m} / \mathrm{s}$. As a comparison to this resulting air velocity, draught-free ventilation in buildings is normally seen as air velocities less than $0.1-0.2 \mathrm{~m} / \mathrm{s}$ [21]. So, it was assessed that the effects of the forced ventilation did not differ significantly from ventilation conditions that might occur in a fuel storage where an autoignited smouldering fire reaches the surface from the interior of the stored material. In the ventilation duct, a sub flow of $0.05 \times$ $10^{-3} \mathrm{~m}^{3} / \mathrm{s}$ (Experiment 4) and $0.37 \times 10^{-3} \mathrm{~m}^{3} / \mathrm{s}$ (Experiment 5) for analysis passed 


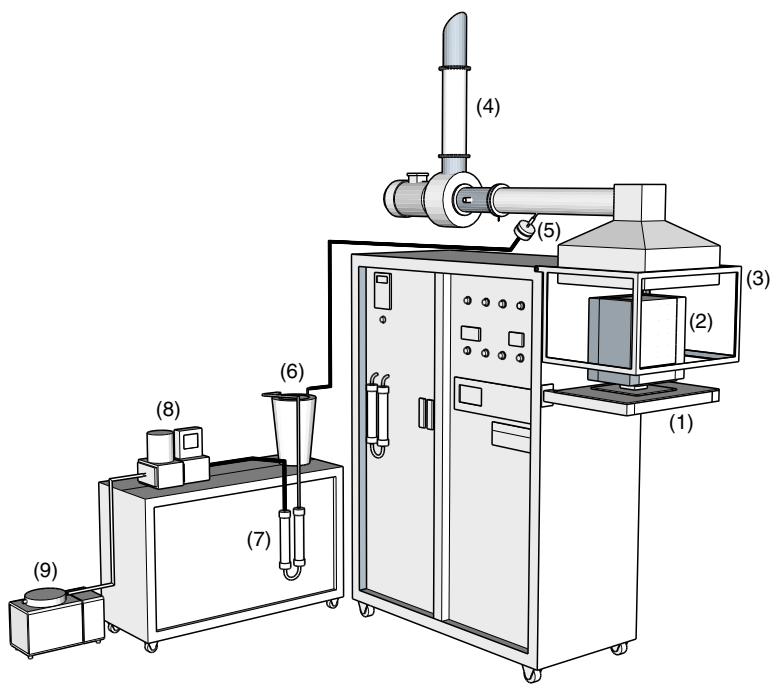

(1) Scale: type TCLC-10KA from Tokyo Sokki Kenkyujo Co.

(2) Setup with cotton package, heating wire Kanthal $0.3 \mathrm{~mm}$ and 80 pcs of thermocouples model G/G-30 Type K, Ø 0.25 from Pentronic AB See also fig. 2

(3) Protection hood

(4) Ventilation duct of cone calorimeter from FTT, Fire Testing Technology

(5) Filter holder and soot sampling filters: Filtertype TISSUEQUARTZ 2500QAT-UP $\varnothing 47 \mathrm{~mm}$ from Sigma-Aldrich Co.

(6) Cold trap

(7) Filters with glass wool and silica gel

(8) Flow meter: OMEGA model FMA-2611A-12

(9) Vaccum pump: Gast Mfg Inc. Model 00A-P101-BN, S/N 1093

\section{Figure 1. Experimental setup of the performed experiments.}

through aerosol filter (5) due to under-pressure caused by a vacuum pump (9). The sub flows were chosen due to isokinetic sampling $\left(0.05 \times 10^{-3} \mathrm{~m}^{3} / \mathrm{s}\right)$ and high quantity sampling $\left(0.37 \times 10^{-3} \mathrm{~m}^{3} / \mathrm{s}\right)$. The solid fire emission aerosols in the sub flow where collected at the filters, which were subsequently extracted and analysed by GCMS. The remaining ventilation flow in the ventilation duct (3) passed to the standard fire gas ventilation connected to the cone calorimeter. Logging of signals from thermocouples and scale was conducted by data logger dataTaker DT85.

The smouldering fire was initiated in the setup, as shown in Figs. 2 and 3, of lightweight concrete blocks (A) on three sides and bottom of the cotton package. The cotton package (B) had a bulk density of $80 \mathrm{~kg} / \mathrm{m}^{3}$, a mass of $600 \mathrm{~g}$ and placed on a net $10 \mathrm{~mm}$ above the lower concrete block. The net had a mesh of $10 \mathrm{~mm}$ and were made of $1 \mathrm{~mm}$ wire. The smouldering fire was initiated by an igniter (C), placed in the lower backside of the cotton package. The igniter is a coil of Kanthal hot-wire, length $600 \mathrm{~mm}$, wrapped around a $10 \mathrm{~mm}$ core of calcium silicate and producing $50 \mathrm{~W}$ during $4.5 \mathrm{~min}$. Temperature inside the cotton package was measured during the experiments by 80 thermocouples (D).

\subsection{Sampling}

Before starting the experiments, the soot sampling connection pipe at the ventilation duct was cleaned with a degreasing agent for removing earlier levoglucosancontaining soot.

Blanks and aerosol samples were collected on $47 \mathrm{~mm}$ quartz filters (Pallflex 2500QAT-UP) during a defined time period and flow rate (Tables 1, 2). Prior to sampling, filters were heated at $900^{\circ} \mathrm{C}$ for $20 \mathrm{~min}$ to remove possibly adsorbed organic compounds from ambient air. After sampling, filters where wrapped in 


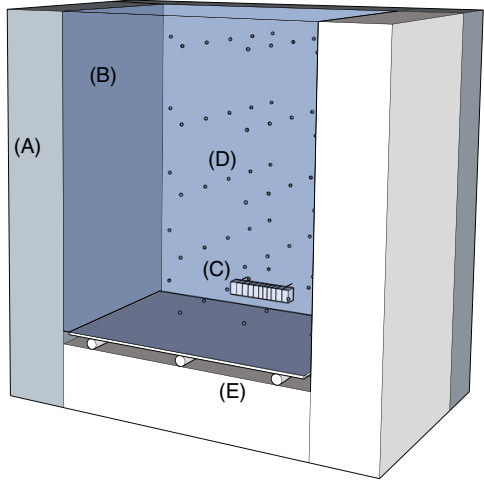

(A) Setup of $50 \mathrm{~mm}$ light weight concrete blocks

(B) Cotton package of $200 \times 150 \times 250 \mathrm{~mm}(\mathrm{LxD} \times \mathrm{H})$

(C) Igniter of heating wire, $50 \mathrm{~W}$ for $4.5 \mathrm{~min}$

(D) 80 thermocouples distributed inside the cotton package

(E) Air inlet: $\mathrm{h}=10 \mathrm{~mm}$ and with a horizontal net

Figure 2. Setup for performing a smouldering fire in cotton.

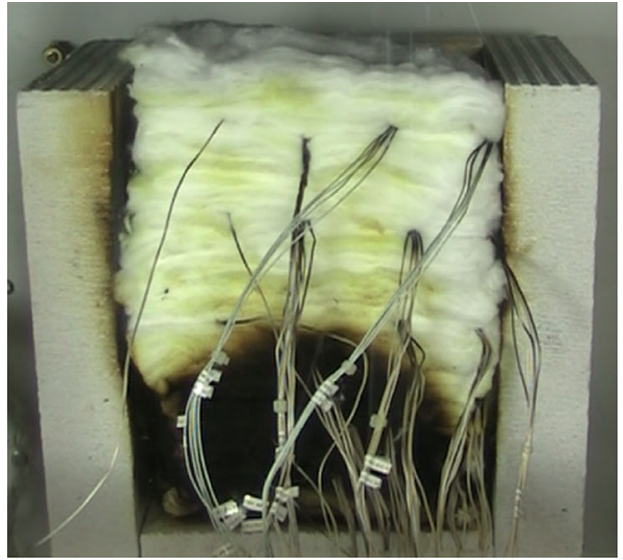

(a)

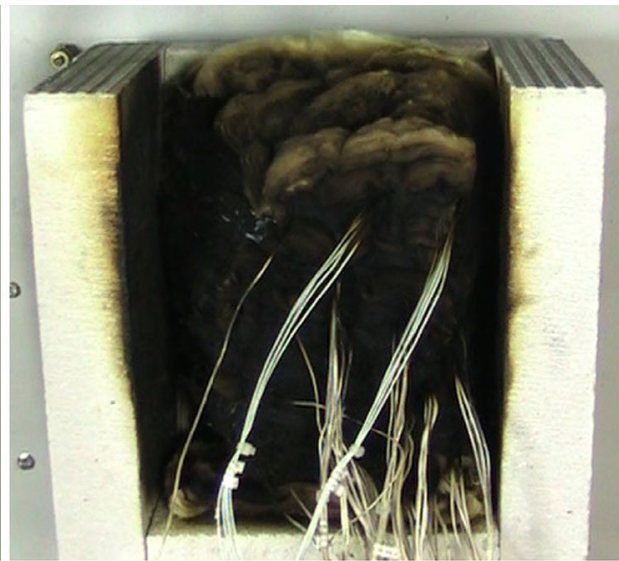

(b)

Figure 3. (a) Smouldering process moving upwards the cotton package 3 h after ignition. (b) Smouldering process has moved through the cotton package $5 \mathrm{~h}$ after ignition.

aluminium foil, sealed in zip-lock bags and stored in freezer until the time of analysis.

80 thermocouples made of thermocouple wire Pentronic Model G7G-30 with a wire thickness of $0.25 \mathrm{~mm}$, where placed inside the cotton package to determine temperature evolvement during the smouldering phase as shown in Fig. 3. The response time of these thermocouples are in the order of seconds, which is sufficient to measure the temperature fluctuations in the sample. Mass loss was recorded using a scale under the cotton stack and a data logger. 


\section{Table 1}

\section{Experiment 4}

\begin{tabular}{|c|c|c|c|c|c|}
\hline Sample & $\begin{array}{l}\text { Sampling } \\
\text { start time } \\
\quad(\min )\end{array}$ & $\begin{array}{l}\text { Sampling } \\
\text { end time } \\
\text { (min) }\end{array}$ & $\begin{array}{l}\text { Total sam- } \\
\text { pling time } \\
\text { (min) }\end{array}$ & $\begin{array}{c}\text { GCMS results [ } \mu \mathrm{g} \text { of } \\
\text { levoglucosan/mL of liquid } \\
\text { extract] }\end{array}$ & $\begin{array}{c}\text { Concentration of } \\
\text { levoglucosan }\left[\mathrm{mg} / \mathrm{m}^{3}\right. \\
\text { (air)] }\end{array}$ \\
\hline 1 & 0 & 30 & 30 & 0.15 & 14.4 \\
\hline 2 & 30 & 60 & 30 & 0.14 & 14.4 \\
\hline 3 & 60 & 90 & 30 & 0.14 & 14.4 \\
\hline 4 & 90 & 120 & 30 & 0.13 & 12.5 \\
\hline 5 & 120 & 180 & 60 & N.D. & N.D. \\
\hline 6 & 180 & 240 & 60 & 0.38 & 18.2 \\
\hline 7 & 240 & 300 & 60 & 0.31 & 15.3 \\
\hline 8 & 300 & 360 & 60 & 0.27 & 12.9 \\
\hline Solid & \multicolumn{5}{|c|}{ Solid sample taken from the front of the cotton package at $5: 00 \mathrm{~h}$ from start of experiment } \\
\hline 9 & 360 & 420 & 60 & N.D. & N.D. \\
\hline 10 & 420 & 480 & 60 & 0.20 & 9.6 \\
\hline
\end{tabular}

Sampling start and end times represent times when collection of aerosol samples on filters were started and ended, respectively. Total sampling time represents the sampling interval. Sampling was performed with a flow of $0.05 \times 10^{-3}$ $\mathrm{m}^{3} / \mathrm{s}$. Total weight of cotton used was $620 \mathrm{~g}$

N.D. = not detected due to high baseline representing other interfering compounds in the sample

Blank corrected data

\section{Table 2}

\section{Experiment 5}

\begin{tabular}{|c|c|c|c|c|c|}
\hline Sample & $\begin{array}{l}\text { Sampling } \\
\text { start time } \\
\quad(\mathrm{min})\end{array}$ & $\begin{array}{l}\text { Sampling } \\
\text { end time } \\
(\min )\end{array}$ & $\begin{array}{l}\text { Total sam- } \\
\text { pling time } \\
\quad(\mathrm{min})\end{array}$ & $\begin{array}{c}\text { GCMS results }[\mu \mathrm{g} \text { of } \\
\text { levoglucosan } / \mathrm{mL} \text { of liquid } \\
\text { extract }\end{array}$ & $\begin{array}{c}\text { Concentration of } \\
\text { levoglucosan }\left[\mathrm{mg} / \mathrm{m}^{3}\right. \\
\text { (air)] }\end{array}$ \\
\hline 1 & 0 & 170 & 170 & 0.29 & 0.7 \\
\hline 2 & 170 & 230 & 60 & 0.47 & 3.0 \\
\hline 3 & 230 & 290 & 60 & 0.45 & 3.0 \\
\hline Solid & \multicolumn{5}{|c|}{ Solid sample taken from the front of the cotton package at 5:00 $\mathrm{h}$ from start of experiment } \\
\hline 4 & 290 & 350 & 60 & 0.50 & 3.4 \\
\hline 5 & 350 & 410 & 60 & 0.37 & 2.4 \\
\hline 6 & 410 & 470 & 60 & 1.21 & 7.9 \\
\hline
\end{tabular}

Sampling start and end times represent times when collection of aerosol samples on filters were started and ended, respectively. Total sampling time represents the sampling interval. Sampling was performed with a flow of $0.37 \times 10^{-3}$ $\mathrm{m}^{3} / \mathrm{s}$. Total weight of cotton used was $610 \mathrm{~g}$

Blank corrected data

\subsection{Extraction and Analysis of Levoglucosan}

Analysis of levoglucosan was carried out by a method of $\mathrm{Wu}$ et al. [22] with some modifications as described earlier by Martinsson et al. [9]. A brief description of the method is given here. Circular punches of $2 \mathrm{~cm}^{2}$ were taken from the aerosol filter samples and extracted with 1:3 mixture of dichloromethane and methanol by 
ultrasonication in three consecutive steps of $45 \mathrm{~min}, 30 \mathrm{~min}$ and $15 \mathrm{~min}$ using $15 \mathrm{~mL}, 10 \mathrm{~mL}$ and $10 \mathrm{~mL}$ of the solvent mixture, respectively. The extracts were pooled, dried under a nitrogen stream and made up to $1 \mathrm{~mL}$ using the same solvent mixture.

Derivatization of levoglucosan was carried out taking $50 \mu \mathrm{L}$ of the filter sample extracts, adding $10 \mu \mathrm{L}$ of N,O-bis(trimethylsilyl)trifluoroacetamide (BSTFA) containing $1 \%$ trimethylsilyl chrloride (TMCS) and $15 \mu \mathrm{L}$ of 1-phenydodecane (internal standard) solution prepared in hexane $(1 \mu \mathrm{g} / \mathrm{mL})$ and the samples were further heated for derivatization in an oven at $80^{\circ} \mathrm{C}$ for $1 \mathrm{~h}$. Samples were analysed immediately after derivatization by an Agilent 6890 series GC with 5973 MS (Agilent Technologies, Palo Alto, USA). A fresh calibration curve and solvent blanks were run for each batch of samples. The following GCMS parameters were used for analysis. HP-5 ms column $(30 \mathrm{~m} \times 0.25 \mathrm{~mm} \times 0.25 \mu \mathrm{m}$ film thickness $), 2 \mu \mathrm{L}$ injection volume using splittless mode and splitless time of $1 \mathrm{~min}$ at $280^{\circ} \mathrm{C}$. Column oven temperature was programed as: $60^{\circ} \mathrm{C}$ for $3 \mathrm{~min}, 190^{\circ} \mathrm{C}$ at a rate of $10^{\circ} \mathrm{C} / \mathrm{min}, 300^{\circ} \mathrm{C}$ at a rate of $30^{\circ} \mathrm{C} / \mathrm{min}$. Transfer line, ion source and quadruple temperatures were $280^{\circ} \mathrm{C}, 250^{\circ} \mathrm{C}$ and $180^{\circ} \mathrm{C}$, respectively. Exact masses of levoglucosan and 1-phenyldodecane i.e. m/z 217.3 and 246.3 were used for quantification using SIM mode.

\section{Results}

\subsection{Identification of Levoglucosan}

In the first phase, initial analyses were made to evaluate the experimental setup and the possibility of detecting levoglucosan in smouldering fires. In these first screening analyses, levoglucosan was successfully identified both in the aerosol particles as well as solid carbonized material that was left as a residue after the initial smouldering process had moved through the material. The experiments revealed the presence of levoglucosan in nearly all the samples. Two examples were excluded due to high baseline. A probable explanation for this high baseline was presence of high concentrations of chemical substances interfering in the analysis.

In the second phase, two quantitative experiments (Experiment 4 and 5) of aerosols and carbonized cotton samples were performed. As shown in Table 1. Experiment 4, sampling start and end times represent times when collection of aerosol samples on filters were started and ended, respectively. Total sampling time represents the sampling interval. Sampling was performed with a flow of $0.05 \times 10^{-3} \mathrm{~m}^{3} / \mathrm{s}$. Total weight of cotton used was $620 \mathrm{~g}$. Levoglucosan was identified in the first $30 \mathrm{~min}$ after starting the smouldering fire. Levoglucosan concentrations were further on detected continuously as the smouldering process developed (see Fig. 3). Solid samples of the carbonized cotton were collected in Experiment 4 and 5, $5 \mathrm{~h}$ after starting the experiments. These carbonized cotton samples $(0.5 \mathrm{mg})$ were analyzed and the concentrations of levoglucosan were found to be $0.48 \mu \mathrm{g} / \mathrm{mg}$ and $0.50 \mu \mathrm{g} / \mathrm{mg}$ of carbonized cotton in Experiment 4 and 5 respectively. 


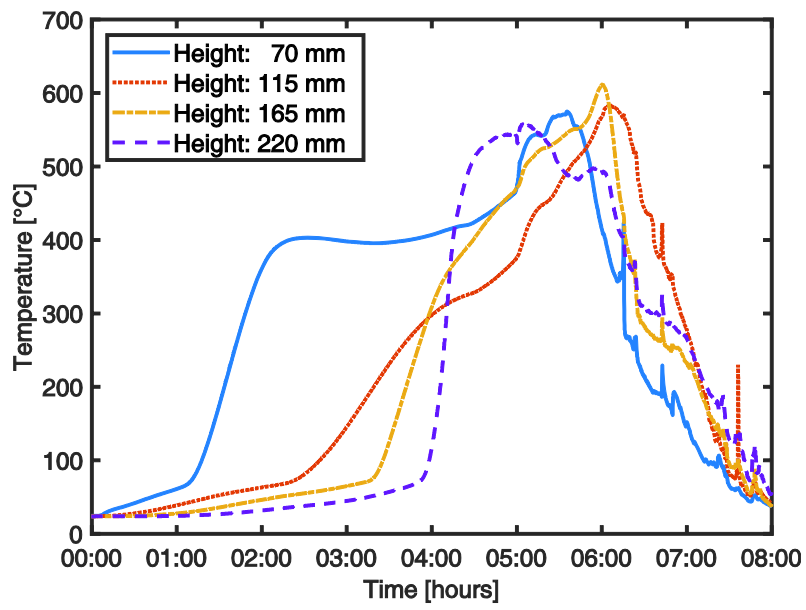

Figure 4. Experiment 4, temperature evolvement for centerline thermocouples in cotton package.

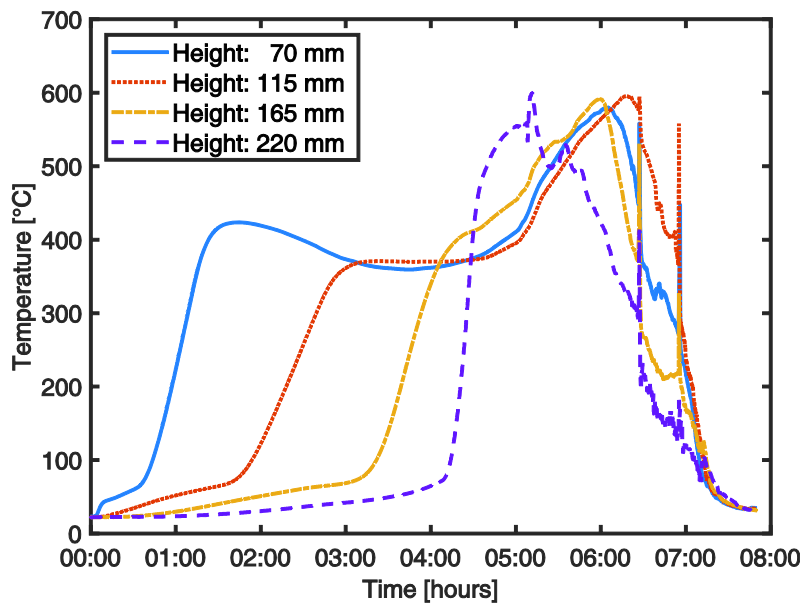

\section{Figure 5. Experiment 5, temperature evolvement for centerline} thermocouples in cotton package.

\subsection{Temperature}

The temperature evolvement in the smouldering cotton follows a similar pattern in both experiments. In Figs. 4 and 5, centerline temperatures located at 70-115$165-220 \mathrm{~mm}$ above the bottom of cotton package appear to increase somewhat during the experiment as the smouldering process moves up through the cotton package. Instantaneous temperatures rises in the temperature graphs indicate that glowing embers appear. The general resulting peak temperatures at $580-600^{\circ} \mathrm{C}$ can be seen as normally occurring temperatures for smouldering fires [4]. 
At $5 \mathrm{~h}$, the smouldering process has moved through the cotton package (see Fig. 3). As shown by Hagen [23] in his doctoral thesis, the appearance of embers sometimes leads to a transition to flaming of the cotton residues left from the initial smouldering. The transition to flaming is possible when both smouldering and secondary char oxidation coexist meaning that the smouldering fire produces gaseous fuel that is ignited by the secondary char oxidation [23]. Hagen [24] also presented in a later paper that the transition to flaming is dependent on density and other boundary conditions.

\subsection{Mass loss}

Initial weights of the cotton in Experiment 4 and 5 were $620 \mathrm{~g}$ and $610 \mathrm{~g}$ respectively. So as the residues after the experiments were weighed to $13 \mathrm{~g}$ and $15 \mathrm{~g}$, resulting in combusted material of $607 \mathrm{~g}$ for Experiment 4 and $595 \mathrm{~g}$ for Experiment 5 (see Fig. 6).

The mass loss rate given in Fig. 7 shows a low mass rate until the initiated smouldering fire has been established at the whole lower cross-section of the cotton package at about 2:00 $\mathrm{h}$. As the smouldering process moves upwards the cotton package, the mass loss rate is quite similar between 3:00 $\mathrm{h}$ and 6:30 $\mathrm{h}$ except for the rise when glowing embers appear at $5 \mathrm{~h}$ and $6: 20 \mathrm{~h}$. The mass loss rate then decreases until only residues are left after $7 \mathrm{~h}$. An interesting observation is that still after the smouldering process has moved through the material at $5 \mathrm{~h}$ (see Fig. 3), the mass loss is still the same during $1.5 \mathrm{~h}$ until 6:30 $\mathrm{h}$ after the start of experiments.

\section{Discussion}

Early detection of fires is crucial to mitigate and extinguish fires at an early stage. Especially, autoignited fires inside material piles in storages are difficult to detect and it can take days and months before the fire is noticed. Earlier research [12]

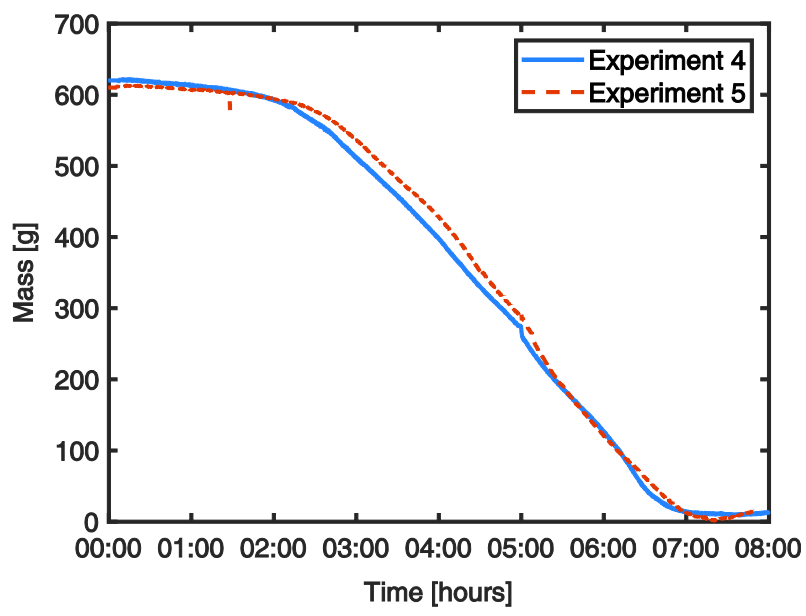

Figure 6. Experiment 4 and 5, mass. 


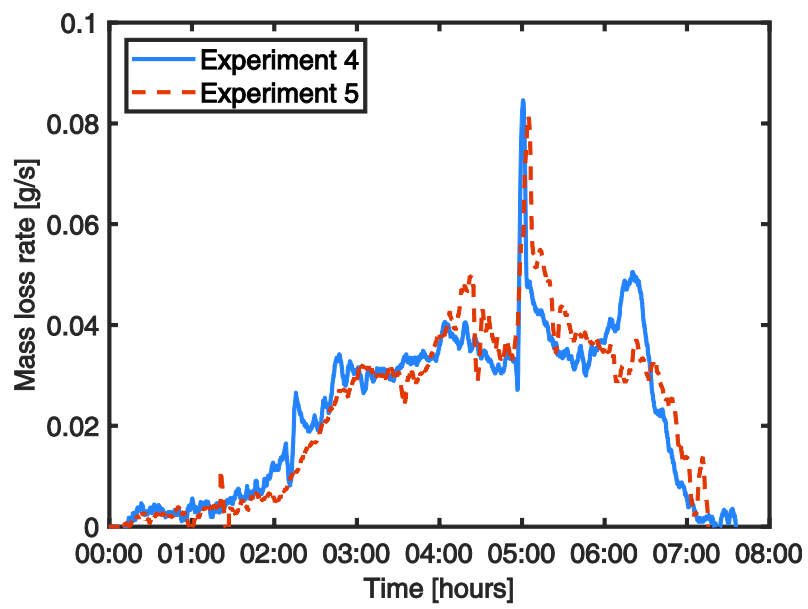

\section{Figure 7. Experiment 4 and 5, mass loss rate.}

has suggested and showed promising results for detecting levoglucosan as a tracer for early detection in cellulose-based materials. The experiments in this paper are performed as a proof of the concept that levoglucosan has a potential as a tracer for early detection of autoignited fires that mostly develop to smouldering fires in fibrous biomaterials.

The results in this paper show that levoglucosan can be detected at a very early stage of a smouldering fire in a cellulose-based material. The most detailed experiment, Experiment 4, detects levoglucosan in a filter sample exposed to fire gases during the initial $30 \mathrm{~min}$ of a small smouldering fire. After $30 \mathrm{~min}$ of ignition by a heating wire, the thermocouples placed within centimeters from the heating wire only registered temperatures under $100^{\circ} \mathrm{C}$. The size of the smouldering fire at this stage is assumed to be some single cubic centimeters and fire gases cannot be seen. Yet, levoglucosan can be detected but it is not clear if levoglucosan evolved from the cotton stack at $100^{\circ} \mathrm{C}$ as the smouldering process developed or if it evolved from the high energy point where the ignition was started by the electric trigger. Nevertheless, the minimum measured concentration of levoglucosan in lab controlled smouldering fire i.e. $0.7 \mathrm{mg} / \mathrm{m}^{3}$ (Table 2) is well above the measured summertime mean concentration of levoglucosan in ambient air of southern Sweden i.e. $0.014 \mu \mathrm{g} / \mathrm{m}^{3}$ as reported in our earlier studies [9].

In smouldering fires, buoyancy forces are normally low due to the low heat intensity. This results in that the produced emissions from such fires are not inclined to spread as fast as emissions from flaming fires. This is a part of the reason of the difficulty in detecting smouldering fires that appears inside biomass materials. The experiments in this paper are based on a forced ventilation flow of $24 \times 10^{-3} \mathrm{~m}^{3} / \mathrm{s}$ passing the experimental setup with an average speed of $0.15 \mathrm{~m} / \mathrm{s}$ and where a sub-flow of 0.05 and $0.37 \times 10^{-3} \mathrm{~m}^{3} / \mathrm{s}$ through the sampling filters in Experiment 4 and 5 respectively were used for detecting levoglucosan. This forced ventilation flow around the setup compels the spread of emissions so that sam- 
pling and detection more easily can be done. In real biofuel storages, there is normally no such forced ventilation. Yet, it should be pointed out that the production and detection of levoglucosan in the first samples are not seen as an effect of forced ventilation around the setup as there were no visual signs of fire at the front surface of the cotton package. The transfer of levoglucosan from the interior of the cotton package was seen as an effect of buoyance forces as would be the case in a real storage. Normal storages of biomaterials do not always have forced ventilation that contributes to carry emissions from smouldering fires so they can be detected as signatures from a fire. Furthermore, no efforts were made to optimize and validate different parameters of sampling procedure used in this experiment that leaves room for further investigations in order to identify possible sampling errors and to estimate concentrations of levoglucosan more precisely. Nevertheless, the observed levoglucosan concentrations were fairly higher than the limit of detection and the findings are significant for further research.

The used setup with a cotton package in the lab-scale experiments differs from real biofuel storages on several parameters; size, geometry, density, material etc. Nevertheless, the basic intent to initiate a smouldering fire by a heating wire in the interior of the material and letting the smouldering process propagate in the material are seen as comparable to the temperature increase in wood pellets leading to autoignited (spontaneous ignition) fires described by Persson et al. [2]. The intent is also to have reproducible experiment, where cotton is seen as a fairly homogeneous material compared to the diversity among materials used as biofuels.

The smouldering fire in the performed experiments shows an interesting behavior of glowing embers that appear after 5:00 h and 6:20 h in both experiments, shown in Figs. 4 and 5. At that point, the smouldering process has moved through the cotton package but still the mass loss is the same as during the movement of smouldering process. This indicates that a similar thermal degradation in the biomass continues for an additional $1.5 \mathrm{~h}$. Some thermocouples registered a temperature rise of almost $200^{\circ} \mathrm{C}$, from $600^{\circ} \mathrm{C}$ to $780^{\circ} \mathrm{C}$, at the presence of the embers. The actual reason for the carbonized material to start glowing is not really clear but suggested as a secondary char oxidation in the residues. The high intensity heat release that causes the glowing embers indicates however that there is still energy-rich material left in the carbonized material after the smouldering process has moved through the cotton package.

Experiments and results in this paper should be seen as an overview that suggests levoglucosan as a potential tracer for an early stage detection of smouldering fires in cotton, a cellulose-based material. The performed experiments were carried out as single experiments for detecting levoglucosan. Nevertheless, the propagation, mass loss and temperature evolvement of the smouldering fire in cotton, using this specific experimental setup has however been repeated numerous times earlier with the same result in unpublished experiments. The temperature evolvement with peak temperatures of around $600^{\circ} \mathrm{C}$ is also normal for smouldering fires. Further smouldering fire experiments with other cellulose-based biomaterials that are used by the industry should be performed with the same purpose, to quantify the presence of levoglucosan in the fire gases emitted from the specific material. 
Detecting levoglucosan in this experimental setup with GCMS for smouldering fire has been determined in this paper for the first time. Yet, the GCMS equipment and technology requires specific knowledge of chemistry, equipment and is time consuming. One analysis of a filter sample takes several hours to perform. Therefore, the challenge is to use these findings and transfer them into full-scale implementation in/at storage facilities where there is a risk for autoignition of biomaterials. The detection technology also needs to be adapted to on-line measurements with sensors that can automatically detect levoglucosan for alerting without any delay. Such sensors can be derived from e-nose technology. Online aerosol mass spectrometry measurements can also provide information for early detection of smouldering fire. Saarnio K. [25] also demonstrated another chromatographic method for online determination of levoglucosan in ambient aerosols using particle-into-liquid sampler coupled to high performance anion-exchange chromatography and mass spectrometry.

Porosity, permeability, aggregate geometry and other factors differ between biomaterials and influences the gas and particle flow from the smouldering fire. The smouldering propagation and how it develops is also depending on the supply of oxygen and temperature. It has been presented by Krause et al. [26] that auto-ignition and smouldering fires may be sustained down to some single percent of oxygen. Measures to enhance the interaction between the emissions and sensors have also to be considered. Forced ventilation flow through the material, pulsation flow of inert gases in the material, extraction of gases and aerosols from material storage interior etc. can be such suggested measures.

\section{Conclusions}

The findings in this paper show that levoglucosan may serve as a tracer in fire emissions for early detection of smouldering fires in cellulose-based materials. Levoglucosan could be detected long time before visual fire emissions or carbonized cotton could be seen. The size of the smouldering fire at first detection was estimated to be a few cubic centimeters. By gas chromatography and mass spectrometry (GCMS) together with reference concentrations of levoglucosan, the actual concentrations of levoglucosan could be determined and quantified in the gases emitted from the smouldering fire. This detection of levoglucosan has earlier been requested by Joseph et al. [12] for ligno-cellulosic materials The findings should be used as a proof of concept and basis in continued research that aims to develop levoglucosan sensors for early detection of fires in cellulose-based materials. Consequences due to developed smouldering fires in biofuels can then easier be dealt with or avoided.

\section{Acknowledgements}

This study is funded by the Research Council of Norway, Project 238329: Emerging Risks from Smoldering Fires (EMRIS). 


\section{Open Access}

This article is distributed under the terms of the Creative Commons Attribution 4.0 International License (http://creativecommons.org/licenses/by/4.0/), which permits unrestricted use, distribution, and reproduction in any medium, provided you give appropriate credit to the original author(s) and the source, provide a link to the Creative Commons license, and indicate if changes were made.

\section{References}

1. Madsen D, Wanke C, Fjellgaard Mikalsen R, Haraldseid I, Villacorta E, Hagen BC, Krause U, Kleppe G, Frette V, Husted B (2016) Emerging risks from smouldering fires: initial results from the EMRIS project. Paper presented at the INTERFLAM 2016, London, 4-6 July 2016

2. Persson H (2013) Silo fires - fire extinguishing and preventive and preparatory measures. MSB-Swedish Civil Contingencies Agency, Karlstad

3. Melin S (2011) Research on off-gassing and self-heating in wood pellets during bulk storage. Wood pellet association of Canada, Revelstoke

4. Rein G (2016) Smoldering combustion. SFPE handbook of fire protection engineering, 5 th edn. Springer, Berlin

5. Nilsson D, Holmstedt G (2008) Kompendium i aktiva system-detektion, Report 7030. Lunds Universitet, Lund, Sweden

6. Andrea MO, Merlet P (2001) Emissions of trace gases and aerosols from biomass burning. Glob Biogeochem Cycles 15(4):955-966

7. Bai X, Johnston P, Brown RC (2013) An experimental study of the competing processes of evaporation and polymerization of levoglucosan in cellulose pyrolysis. J Anal Appl Pyrol 99:130-136. https://doi.org/10.1016/j.jaap.2012.10.012

8. Cordell RL, White IR, Monks PS (2014) Validation of an assay for the determination of levoglucosan and associated monosaccharide anhydrides for the quantification of wood smoke in atmospheric aerosol. Anal Bioanal Chem 406(22):5283-5292. https:// doi.org/10.1007/s00216-014-7962-x

9. Martinsson J, Abdul Azeem H, Sporre MK, Bergström R, Ahlberg E, Öström E, Kristensson A, Swietlicki E, Eriksson Stenström K (2017) Carbonaceous aerosol source apportionment using the Aethalometer model-evaluation by radiocarbon and levoglucosan analysis at a rural background site in southern Sweden. Atmos Chem Phys 17(6):4265-4281. https://doi.org/10.5194/acp-17-4265-2017

10. Simoneit BRT, Schauer JJ, Nolte CG, Oros DR, Elias VO, Fraser MP, Rogge WF, Cass GR (1999) Levoglucosan, a tracer for cellulose in biomass burning and atmospheric particles. Atmos Environ 33(2):173-182

11. Mochida M, Kawamura K (2004) Hygroscopic properties of levoglucosan and related organic compounds characteristic to biomass burning aerosol particles. J Geophys Res Atmos. https://doi.org/10.1029/2004JD004962

12. Joseph P, Bakirtzis D, Vieille A (2015) An "electronic nose" as a potential device for fire detection of forest product fire loads in enclosures. Wood Mater Sci Eng 10(1):130 144. https://doi.org/10.1080/17480272.2014.939713

13. Genberg J, Hyder M, Stenström K, Bergström R, Simpson D, Fors EO, Jönsson JÅ, Swietlicki E (2011) Source apportionment of carbonaceous aerosol in southern Sweden. Atmos Chem Phys 11(22):13575-13616 
14. Kanakam P, Hussain SM, Chakravarthy ASN (2015) Electronic noses: forestalling fire disasters: a technique to prevent false fire alarms and fatal casualties. In: 2015 IEEE international conference on computational intelligence and computing research (ICCIC), Madurai, India 10-12 December 2015. IEEE, pp 1-6. https://doi.org/10.1109/i ccic. 2015.7435629

15. Hagen BC, Frette V, Kleppe G, Arntzen BJ (2011) Onset of smoldering in cotton: effects of density. Fire Saf J 46(3):73-80. https://doi.org/10.1016/j.firesaf.2010.09.001

16. Rein G (2009) Smouldering combustion phenomena in science and technology. Int Rev Chem Eng 1:3-18

17. Blomqvist P, van Hees P (2006) Spontaneous ignition of biofuels - an experimental investigation through small and large-scale tests, Report SP 2006:41. SP Swedish National Testing and Research Institute, Borås, Sweden

18. Blomqvist P, Persson H, Van Hees P, Holmstedt G, Göransson U, Wadsö L, Sanati M, Rupar-Gadd K (2007) An experimental study of spontaneous ignition in storages of wood pellets. Paper presented at the Fire and Materials Conference 2007, San Francisco, USA, 29th-31st January 2007

19. NIST Cone Calorimeter. NIST, National Institute of Standards and Technology. http s://www.nist.gov/laboratories/tools-instruments/cone-calorimeter. Accessed 1 Dec 2017

20. International Organization for Standardization (2015) ISO 5660-1:2015 Reaction-to-fire tests - heat release, smoke production and mass loss rate

21. Swedish Standards Institute SIS (2006) SS-EN ISO 7730:2006 Ergonomics of the thermal environment

22. Wu J, Hu R, Yue J, Yang Z, Zhang L (2008) Study on the derivatization process using $\mathrm{N}$-O-bis-(trimethylsilyl)-trifluoroacetamide, N-(tert-butyldimethylsilyl)-N-methyltrifluoroace tamide, trimethylsilydiazomethane for the determination of fecal sterols by gas chromatography-mass spectrometry. Int J Chem Mol Nucl Mater Metall Eng 4:136140

23. Hagen BC (2013) Onset of smoldering and transition to flaming. $\mathrm{PhD}$ thesis, University of Bergen, Norway

24. Hagen BC, Frette V, Kleppe G, Arntzen BJ (2014) Transition from smoldering to flaming fire in short cotton samples with asymmetrical boundary conditions. Fire Saf $\mathbf{J}$ 71:69-78

25. Saarnio K, Teinilä K, Saarikoski S, Carbone S, Gilardoni S, Timonen H, Aurela M, Hillamo R (2013) Online determination of levoglucosan in ambient aerosols with particle-into-liquid sampler-high-performance anion-exchange chromatography-mass spectrometry (PILS-HPAEC-MS). Atmos Meas Tech 6:2839-2849

26. Malow M, Krause U (2009) Smoldering combustion of solid bulk materials at different volume fractions of oxygen in the surrounding gas. Paper presented at the 9th International Symposium on Fire Safety Science, Karlsruhe, Germany, 21-26 September 2008

Publisher's Note Springer Nature remains neutral with regard to jurisdictional claims in published maps and institutional affiliations. 